\title{
EL MISTERIOSO IRLANDÉS
}

\section{David Gallagher}

En este ensayo sobre la novela más reciente de Mario Vargas Llosa, El sueño del celta, se sostiene que aun cuando no se pueda decir que es la mejor del Nobel de Literatura (porque no hay una que lo sea) sí es una novela cúspide: una novela escrita con la sabiduría, la compasión y la entereza de quien ha vivido todas las pasiones y ha llegado a un entendimiento profundo de lo que es el ser humano, con todas sus grandezas y miserias. El ensayo parte recordando la conversación que David Gallagher sostuvo con Vargas Llosa, varios años antes de que éste escribiese El sueño del celta, sobre la historia del irlandés Roger Casement y sobre las reflexiones que suscita esa historia respecto a la "verdad" de los hechos. A continuación se aborda la particular configuración entre historia, biografía y novela que se da en El sueño del celta, así como

DAVID Gallagher. Educado en Oxford, fue luego profesor de literatura latinoamericana del St. Antony's College de esa misma Universidad. Actualmente es socio de ASSET-CHILE y combina sus actividades como ensayista y crítico con las de banca de inversiones. Colabora con TLS (The Times Literary Supplement) y es columnista de El Mercurio de Santiago. Ha publicado Modern Latin American Literature (Oxford University Press, 1973), Improvisaciones (Centro de Estudios Públicos, 1992), Otras improvisaciones (El Mercurio-Aguilar, 2004) y numerosos ensayos. Es miembro del Consejo Directivo del Centro de Estudios Públicos. David@assetchile.com. 
las similitudes ideológicas entre el personaje Casement y el propio Vargas Llosa. Luego se compara la exploración del mal que hace el Casement de Vargas Llosa con la que hace Marlow, protagonista de Conrad en El corazón de las tinieblas. Finalmente, se describen notables parecidos entre la figura del Quijote y el Casement de Vargas Llosa, planteándose que nunca antes había Vargas Llosa diseñado un personaje tan complejo y tan proteico como lo es su Casement en El sueño del celta.

\section{Introducción}

$\mathrm{E}_{\mathrm{r}}$

ra febrero del 2007. Estábamos con Mario y Patricia Vargas Llosa, y un grupo de sus amigos, navegando por los ríos amazónicos del Perú. Tórridos ríos tropicales como los de La casa verde, de Pantaleón, de El hablador. Habíamos zarpado en Iquitos, y habíamos subido por el río Marañón para después tomar el Ucayali. De vez en cuando salíamos en lancha para meternos en algún afluente pequeño, para penetrar la selva tupida, y acceder a alguna laguna escondida, para admirar las victorias regias, esas plantas cuyas inmensas hojas verdes flotan en el agua, y dejan asomar, entre ellas, unos nenúfares de asombrosos pétalos blancos o rojos.

En una de esas salidas en lancha, al atardecer, Mario empezó a hablar del boom del caucho que se dio en la Amazonía peruana; de la época, hacia 1910, en que Iquitos era tan próspero, que construían en su plaza una casa diseñada nada menos que por Gustave Eiffel. Nos contó en especial de Julio C. Arana, el magnate cauchero cuya empresa, la Peruvian Amazon Company, estaba cotizada en la Bolsa de Londres, y que se había hecho inmensamente rico explotando el caucho de la selva del Putumayo, hasta que un observador irlandés hizo un lapidario informe en que desenmascaró las brutalidades con que la gente de Arana forzaba a los indios de la selva a trabajar. Era el mismo irlandés que había denunciado la crueldad con que los agentes de Leopoldo II, el rey de los belgas, se imponían a los nativos del Congo, también para obligarlos a juntar caucho. “Cómo es que se llamaba ese irlandés, Patricia?”, le pregunta Mario a su mujer. “¿Ese irlandés que en Matadi, en 
pleno Congo, conoció a Conrad, en ese viaje a África de Conrad que inspiró El corazón de las tinieblas?". Patricia tampoco se acordaba al comienzo, pero poco a poco le fue saliendo el nombre. "Casement", dijo ella, finalmente. "Roger Casement". Y allí Mario contó la historia de este singular hombre, de una familia protestante de Irlanda, pero de madre católica, que se había desempeñado como un agente de la Corona británica, que había sido ennoblecido por el Rey Jorge V por su trabajo ejemplar en pro de los derechos humanos de los nativos del Congo y del Putumayo, pero que después, en plena Primera Guerra Mundial, había partido para Alemania, para tratar de juntar, entre los prisioneros de guerra tomados por los alemanes a voluntarios para la constitución de una brigada irlandesa, que con la ayuda de los alemanes, liberara a Irlanda. Detenido por los ingleses al desembarcar en Irlanda en un submarino alemán, Casement, a los 51 años, había sido ejecutado en Londres por traidor, el 3 de agosto de 1916.

Con ese don narrativo natural que tiene, Mario nos tenía concentrados mientras contaba la historia y apenas nos dimos cuenta que ya había anochecido cuando volvimos al barco que nos esperaba en el Ucayali. Ya a bordo, Mario nos admitió que más de alguna vez había pensado escribir una novela sobre Casement, pero ya no creía que lo iba a poder hacer. Lo veía como una tarea demasiado inmensa, una tarea inabordable.

No me acuerdo cuándo fue que me llegó la noticia de que el intrépido novelista la estaba emprendiendo a pesar de todo. Lo primero que supe fue que Mario se había puesto a estudiar todo lo que podía sobre Casement. La noticia me alegró mucho, por lo que prometía. Me alegró en parte porque Casement de alguna manera me había acompañado durante toda una vida. En el colegio benedictino en que estudié en Inglaterra, era un caso obligado de estudio. En un colegio católico, en que muchos compañeros eran irlandeses, la ejecución de Casement era un tema emblemático. ¿Era Casement, quien por cierto se convirtió al catolicismo antes de morir, un héroe o un traidor? Era la pregunta sobre la cual teníamos que escribir un ensayo. Nos obligaba a reflexionar. Para los compañeros irlandeses era un héroe y para los ingleses, en la década postcolonialista de los sesenta, no era tan claro que fuera un traidor, ya que luchaba por la legítima independencia de su país. Por otro lado en Inglaterra era cada vez más numerosa la gente que quería 
abolir la pena de muerte, y para ella, la ejecución de Casement provocaba vergüenza. Casement en fin era un tema que nos ayudaba a entender lo que es la base de toda buena educación, sobre todo cuando se trata de historia: la conveniencia de someter todo prejuicio, toda creencia, toda afirmación, al más acucioso escrutinio; y la de entender que mucho de lo que se tiene por verdad absoluta es relativo, porque lo que es cierto para uno no lo es para otro.

Claro que me alegré que Mario estuviera escribiendo sobre Casement, no sólo por razones personales egoístas. Me parecía un tema ideal para él. La investigación que había hecho Casement de las atrocidades del Putumayo le permitirían volver a la selva peruana, que siempre le había inspirado un lenguaje sensual, evocativo, exuberante, un lenguaje denso y frondoso como la selva misma. Por otro lado Casement era, como Mario, un adalid de los derechos humanos, en su caso los de nativos que en esa época eran apenas considerados como humanos. Además, en sus ensayos, Mario había desenmascarado, como Casement, las vilezas de Leopoldo II en el Congo. Enseguida, estaba la interesante amistad de Casement con Conrad. Vargas Llosa había descubierto a Casement a través de Conrad, un escritor que él ha leído con manifiesto placer, y cuyas huellas aparecen, a mi parecer, en esa joya de novela corta que es La historia de Mayta. Más que nada, Casement era un personaje proteico: un hombre multifacético, insondablemente complejo, ideal para un novelista. Tenía la doble vida tortuosa de quien sirve a un país y sueña en secreto con servir a otro. También estaba el tema de los "Black Diaries", los "diarios negros", unos diarios de vida que le habrían encontrado en su departamento de Londres cuando ya estaba preso, diarios en que Casement habría anotado con inusual crudeza los escabrosos detalles de una vida homosexual promiscua y secreta, librada muchas veces con menores de edad, y tan secreta que hasta sus más íntimos amigos la ignoraban. Hasta ahora, hay expertos en Casement que piensan que los ingleses falsificaron estos diarios para desprestigiarlo, para evitar que se convirtiera en un mártir de la causa irlandesa. Para un novelista como Vargas Llosa, el hecho de que haya diarios íntimos que puedan haber sido falsificados toca la médula de los enormes desafíos epistemológicos que enfrenta un novelista cuando pretende convertir en ficción la historia. 
Publicado menos de cuatro años después de esa conversación memorable en un río amazónico, El sueño del celta valió la espera. No sé si es la mejor novela escrita por Vargas Llosa. No creo que haya una que lo sea. Sí creo que es una novela cúspide, una novela escrita con la sabiduría, la compasión, la entereza de quien ha vivido todas las pasiones, $\mathrm{y}$ ha llegado a un entendimiento profundo de lo que es el ser humano, en todas sus grandezas y sus miserias.

\section{Las fases de una vida}

La novela tiene una estructura bastante simple. Comienza en Pentonville, la cárcel londinense en que Casement está recluido, mientras espera el veredicto del Primer Ministro Asquith y su gabinete. ¿Le conmutarán la sentencia de muerte? Los capítulos se alternan entre los que están situados en Pentonville, a los que volvemos siempre, y los que nos llevan, o a la infancia de Casement en Irlanda, o a sus viajes al Congo y al Putumayo, o de nuevo a Irlanda, la de su madurez, o, hacia el final, a Alemania, en búsqueda de la brigada irlandesa, y de allí de nuevo a Irlanda, donde desembarca por última vez y lo detienen. Pero en cada capítulo puede haber una mirada a uno anterior o a uno por venir. Muchas veces el pretexto es un sueño. La mañana en que llega a Iquitos por primera vez, Casement, atribulado por una enfermedad de los ojos, y por dolores de artritis, elige descansar en vez de almorzar. Se duerme y sueña detenidamente con el año y medio que pasó en Irlanda entre 1904 y 1905. Así en plena selva peruana viajamos a la lejana y brumosa isla con que, en realidad, el empedernido celta que es Casement está soñando siempre. Pero a pesar de que el autor la va revelando en múltiples relatos paralelos, la vida de Casement progresa en forma relativamente lineal en la novela, salvo que volvemos siempre a Pentonville, a la celda en que Casement no puede ver ni la luz del día. Todos los caminos conducen a esta última morada en que Casement se va preparando para la muerte.

La mirada es siempre la de Casement. Rara vez Vargas Llosa se ha metido tanto en la cabeza de un personaje. Pero a la vez el narrador mantiene una sutil distancia. Desde ya usa la tercera persona. Además nos va revelando de a poco la doble vida sexual de Casement: es el narrador, no Casement, el que va dosificando la revelación de una vida secreta que para Casement es vergonzosa. De a poco vienen aparecien- 
do los diarios secretos, los diarios negros. Allí el narrador, y el autor, toman una decisión. Deciden que los diarios no son falsos, pero que sí lo son algunos de los hechos que describen. O sea lo que en ellos describe Casement a veces corresponde a algo que hizo, a veces sólo a una fantasía que tuvo. A medida que avanza la novela, el homosexualismo de Casement se va sincerando cada vez más a través de recuerdos y de sueños. Lo que al comienzo es sólo insinuado con sutileza termina invadiendo la página.

En la novela aparecen muchos personajes con que Casement tiene discusiones, en que pone a prueba sus ideas. Estas discusiones son pequeñas joyas. Son como pequeñas obras de teatro. Uno se puede imaginar a Vargas Llosa, el actor, en el escenario, jugando el papel de Casement, debatiendo, discutiendo con cada contraparte. Con el Padre Carey, el capellán de la cárcel, de Irlanda y del catolicismo. Con la historiadora Alice Stopford Green, de Irlanda y de Conrad. Con Theodore Horte, un misionero bautista en el Congo, o con Edmund D. Morel, un periodista, o con Herbert Ward, un escultor, de su desilusión con el colonialismo, y de su descubrimiento del mal, del grado de bajezas a la que es capaz de caer el ser humano. Con Ward, también, de Irlanda: Ward ridiculiza el creciente nacionalismo de Casement, "su patriotismo de oropel - banderas, himnos, uniformes - que, le decía, representaba, siempre, a la corta o a la larga, un retroceso hacia el provincialismo, el espíritu de campanario, y la distorsión de los valores universales" ${ }^{\text {". Uno }}$ sospecha que el mismo Vargas Llosa, siempre contrario al nacionalismo, comparte estas ideas de Ward, pero el narrador nunca permite que se inmiscuyan las ideas de Vargas Llosa en su exploración rigurosa de la mente de Casement.

A veces los interlocutores de estas piezas teatrales son amigos de Casement, amigos íntimos como Morel o Ward (aunque ambos se negaran al final a firmar la petición para conmutar su sentencia, por estar escandalizados con su incursión a Alemania), o Stopford Green, y muy afines a él. A veces son personajes que están en las antípodas de Casement, como Víctor Israel, un cauchero judío a quien él conoce en una mesa de póquer, en un barco que los lleva de Brasil a Iquitos. Casement ha defendido a los indios de la Amazonía, objetando la forma en que los sacan por la fuerza "de sus aldeas, donde han vivido años o siglos", y le pregunta a Israel si

${ }^{1}$ Mario Vargas Llosa, El sueño del celta, 2010, p. 305. 
a él le gustaría que a fuerza de torturas lo sacaran de sus quehaceres para obligarlo a juntar caucho en la selva. "-Yo no soy un salvaje que vive desnudo, adora el yacumama y ahoga en el río a sus hijos si nacen con el labio leporino - repuso el cauchero, con una risotada sardónica que acentuaba su disgusto- ¿ ¿Pone usted en un mismo plano a los caníbales de la Amazonía y a los pioneros, empresarios y comerciantes que trabajamos en condiciones heroicas y nos jugamos la vida por convertir estos bosques en una tierra civilizada?"2.

Así una y otra vez en esta novela se van dando estos pequeños diálogos en que se debaten ideas, sobre los derechos humanos, la identidad de las naciones, las causas de la maldad, el alcance de la civilización, o la naturaleza del colonialismo, en un contexto en que lo que pensaba Casement era osado y novedoso: él fue pionero en su época en cuestionar el concepto de progreso, de desarrollo.

\section{Entre la novela y la biografía}

Vargas Llosa se ha sentido cómodo a través del tiempo escribiendo novelas basadas en personajes históricos. Sólo en el último decenio, están los notables casos de Trujillo en La fiesta del Chivo, o de Flora Tristán y Gauguin en El Paraíso en la otra esquina. En algunas ha entremezclado a los personajes históricos con personajes ficticios más que en otras. Lo ha hecho con el aplomo de un escritor cuyos relatos irradian todas las virtudes de la verosimilitud. Lejos de cuestionar, como un Borges, el status ontológico de sus textos, lejos de postularlos como ontológicamente precarios, Vargas Llosa siempre nos ha convencido que sus ficciones son más reales que la realidad, que sin ellas simplemente no veríamos las verdades ocultas que desenmascaran. Y es así: conozco a lectores que nunca habían entendido la vileza y la degradación de la tortura hasta leer La fiesta del Chivo.

En El sueño del celta, la confluencia entre historia, biografía y novela es muy particular. Por un lado la novela es una clara vindicación de Casement. Con la sed que se le conoce de verdad y justicia, Vargas Llosa ha escrito una novela que deja a Casement como héroe. Un héroe fallido tal vez, pero héroe de todas maneras. Héroe y gran hombre. La novela se encarga de corregir mentiras, de enmendar ficciones que se

\footnotetext{
${ }^{2}$ Ibídem, pp. 206-207.
} 
habían quedado como parte de su historia, y lo hace con la autoridad de quien ha estudiado la vida de Casement con la acuciosidad y disciplina que se le conocen a Vargas Llosa. Por ejemplo, cuando Casement desembarca en Irlanda un Viernes Santo de 1916, no es para fomentar o liderar el famoso Alzamiento de Semana Santa, como después se afirmó en el juicio. Es más bien para pararlo, porque Casement no había podido conseguir ayuda militar alemana, y estaba convencido que sin ella el alzamiento no podía sino fracasar. Casement pondera la ironía de la equivocación desde su celda.

Sólo veía un cuadradito minúsculo de cielo grisáceo y pensaba en la gran paradoja: había sido juzgado y condenado por traer armas para un intento de secesión violenta en Irlanda, y, en realidad, él había emprendido ese viaje riesgoso, acaso absurdo, desde Alemania hasta las costas de Tralee, para tratar de evitar ese alzamiento que, desde que supo que se preparaba, estaba seguro que fracasaría. ¿Sería así toda la Historia? ¿La que se aprendía en el colegio? ¿La escrita por los historiadores? Una fabricación más o menos idílica, racional y coherente de lo que en la realidad cruda y dura había sido una caótica y arbitraria mezcla de planes, azares, intrigas, hechos fortuitos, coincidencias, intereses múltiples, que habían ido provocando cambios, trastornos, avances y retrocesos, siempre inesperados y sorprendentes respecto a lo que fue anticipado o vivido por los protagonistas ${ }^{3}$.

Uno recuerda acá las ironías del narrador de Tolstoi en La guerra y la paz, en cuanto a la brecha que separa lo que realmente pasó con lo que los historiadores dicen que pasó, y como el de Tolstoi, el narrador de Vargas Llosa claramente pretende corregir la historia con su ficción, con la ventaja de que es mucho más verosímil que el de Tolstoi, porque es más ecuánime: sus ironías son menos sesgadas que aquellas con que el narrador de Tolstoi pretende destruir a Napoleón. Por su lado Casement está siempre esmerado en registrar correctamente la historia, anotando todo lo que ve en el Congo o en el Putumayo. "Si no hubiera llevado en sus cuadernos un registro tan minucioso de fechas, lugares, testimonios y observaciones, en su memoria todo aquello andaría revuelto y trastocado", comenta el narrador ${ }^{4}$.

\footnotetext{
${ }^{3}$ Ibídem, p. 130

${ }^{4}$ Ibídem, p. 94.
} 
Sin embargo en su afán de corregir la historia y, de alguna manera, concederle a Casement el juicio justo que nunca tuvo, ¿es enteramente fidedigno el narrador de Vargas Llosa? ¿No está sesgado también? Por otro lado Vargas Llosa está obligado a tomar una decisión de novelista respecto a los "diarios negros". Cuenta en su Epílogo que cuando el gobierno británico permitió que investigadores, entre ellos grafólogos, los examinaran, las opiniones sobre su autenticidad siguieron divididas. "Lo que no está mal", acota Vargas Llosa. "No está mal que ronde siempre un clima de incertidumbre en torno a Roger Casement, como prueba de que es imposible llegar a conocer de manera definitiva a un ser humano, totalidad que se escurre siempre de todas las redes teóricas y racionales que tratan de capturarla"5. Y de allí revela la decisión de novelista que él toma. "Mi propia impresión" dice, "—la de un novelista, claro está- es que Roger Casement escribió los famosos diarios pero no los vivió, no por lo menos integralmente, que hay en ellos mucho de exageración y ficción, que escribió ciertas cosas porque hubiera querido pero no pudo vivirlas"6.

Es así que, con la autoridad que le da el evidente cariño que siente por Casement, el narrador de El sueño del celta a veces lo tiene anotando en su "diario negro" el crudo resumen de un encuentro sexual que quiso, pero no pudo tener, y otras a veces, en el mismo lenguaje crudo, uno que sí tuvo. En una escala que hace en Barbados, lo turba a Casement un "muchacho muy joven, adolescente, de quince o dieciséis años". El narrador nos cuenta que "de su ajustado pantalón de baño, emergían unos muslos lampiños y elásticos que a Roger le causaron un comienzo de vértigo"7. Roger lo invita a tomar un helado, pero el joven no acepta. De regreso en su hotel, Roger escribe en su diario, "en el lenguaje vulgar y telegráfico que utilizaba para los episodios más íntimos: 'Baños públicos. Hijo de clérigo. Bellísimo. Falo largo, delicado, que se entiesó en mis manos. Lo recibí en mi boca. Felicidad de dos minutos" ". Casement de allí se masturba y se baña. El día siguiente, otra vez en los baños públicos, tiene más suerte. Esta vez lo que escribe no es fantasía sino verdad. Vive la felicidad por dos libras esterlinas. "Baños públicos. Stanley Weeks: atleta, joven, 27 años. Enorme, du-

\footnotetext{
${ }^{5}$ Ibídem, p. 449.

${ }^{6}$ Ibídem, p. 449.

7 Ibídem, p. 295.

${ }^{8}$ Ibídem, p. 296.
} 
rísimo, 9 pulgadas por lo menos. Besos, mordiscos, penetración con grito. Dos pounds" . Así por cierto son los diarios negros de Casement: telegráficos, personales, con sentido sólo para su autor, quien aparece en ellos como un incansable coleccionista, real o imaginario, de hombres. Sus diarios son comparables a esas telegráficas "colecciones" de pájaros que hacen los ornitólogos en su libro de pájaros, cuando anotan cada pájaro nuevo que ven.

Es interesante por cierto la forma abierta y comprensiva en que Vargas Llosa describe el homosexualismo de Casement. El autor de Conversación en La Catedral, que nos hacía creer que la vida homosexual secreta de un Fermín Zavala era la prueba de su abyecta corrupción moral, tanto por el doblez y la hipocresía implicados en ella como por el homosexualismo mismo, en El sueño del celta nos presenta a un homosexual de vida doble que es muy querible. Vargas Llosa lo acompaña en sus aventuras y en sus sufrimientos. Nos muestra cómo Casement recién se libera un poco cuando llega, virgen, a África. "África", explica el narrador, "aquel continente atroz pero hermosísimo, de enormes sufrimientos, era también tierra de libertad, donde los seres humanos podían ser maltratados de manera inicua, pero, asimismo, manifestar sus pasiones, fantasías, deseos, instintos y sueños, sin las bridas y prejuicios que en Gran Bretaña ahogaban el placer" ${ }^{10}$. Cabe acordarse de que Casement llega a África en 1884, once años antes de que empezara en Inglaterra el primer juicio a Oscar Wilde, por "delitos" semejantes a los de Casement. No es sorprendente, para la época en que vivió, que Casement siempre sufra con su homosexualismo. Llevado por un impulso irresistible, sale a la calle para levantar a un muchacho pero después, ya aliviado, siente asco. Sin embargo, a pesar de que a veces se autoimpone meses de abstinencia, está feliz cuando le vuelve el deseo. "Vuelvo a ser yo mismo", se dice ${ }^{11}$. Como en la escena de ardor lesbiano en El Paraíso en la otra esquina, entre Flora Tristán y su amiga Olympia, Vargas Llosa nos brinda escenas homosexuales tremendamente sensuales, de fuerte carga erótica, sobre todo cuando Casement se duerme y lo invaden sus sueños. Pero nunca se libera del todo de la culpa, ni en los sueños, como cuando, todavía en sus primeros días en Iquitos, habiendo entrevistado recién a Eponim Thomas Campbell, el

\footnotetext{
${ }^{9}$ Ibídem, p. 298.

${ }^{10}$ Ibídem, pp. 280, 281.

${ }^{11}$ Ibídem, p. 113.
} 
capataz de Barbados que le cuenta de las terribles atrocidades que él mismo ha sido obligado a perpetrarles a los indios, Casement se pone a descansar un rato. Lo que viene es magnífico. Sin duda un festín para analistas.

Soñó con su madre en un lago de Gales. Brillaba un sol tenue y esquivo entre las hojas de los altos robles, y, agitado, con palpitaciones, vio asomar el joven musculoso al que había fotografiado esta mañana en el malecón de Iquitos. ¿Qué hacía en aquel lago galés? ¿O era un lago irlandés, en el Ulster? La espigada silueta de Anne Jephson desapareció. Su desasosiego no se debía a la tristeza y la piedad que provocaba en él aquella humanidad esclavizada en el Putumayo, sino a la sensación de que, aunque no la veía, Anne Jephson andaba por los alrededores espiándolo, desde aquella arboleda circular. El temor, sin embargo, no atenuaba la creciente excitación con que veía acercarse el muchacho de Iquitos. Tenía el torso empapado por el agua del lago de cuyas aguas acababa de emerger como un dios lacustre. A cada paso sus músculos sobresalían y había en su cara una sonrisa insolente que lo hizo estremecerse y gemir en el sueño. Cuando despertó, comprobó con asco que había eyaculado. Se lavó y se cambió el pantalón y el calzoncillo. Se sentía avergonzado e inseguro ${ }^{12}$.

Algo parecido le pasará también al Casement de Vargas Llosa en Pentonville, cuando tendrá un sueño erótico nada menos que con Eivind Adler Christensen, un joven noruego que lo acompaña a Alemania y que después lo traiciona. O sea, tiene en su celda un sueño erótico nada menos que con uno de los responsables de su inminente ejecución ${ }^{13}$.

Vargas Llosa por cierto le inyecta a su vez un toque de humor a la vida sexual torturada de Casement. En 1913, en una escala en Las Palmas, se encuentra "con un moreno de cabellos ensortijados recién salido de la adolescencia"14. Tras tomar con él un trago en un bar, van caminando hacia un hotel cuando "Roger sintió una cuchillada en la cadera que lo hizo encogerse en la baranda de una ventana [...]. Debió sentarse en el suelo, doblado en dos"15. En este mundo de alto riesgo al que se expone Casement, uno cree al comienzo que Miguel,

\footnotetext{
12 Ibídem, pp. 163-164.

${ }^{13}$ Ibídem, p. 194.

${ }^{14}$ Ibídem, p. 379.

15 Ibídem, p. 380.
} 
o alguien, lo ha acuchillado, pero resulta que ha tenido un ataque de artritis. Miguel huye despavorido. La mañana siguiente, al desayuno, Roger escribirá, en su diario, "con letra apretada", que hizo el amor con Miguel varias veces. En sus descripciones de un Casement que se va envejeciendo, y que es asediado constantemente por la mala salud, está siempre el ojo clínico que ha tenido Vargas Llosa, en su madurez como escritor, por las humillaciones con que el cuerpo socava a la voluntad.

Para escribir esta novela biográfica, Vargas Llosa, tal como lo hizo con Gauguin y Flora Tristán, visitó todos los lugares en que Casement vivió, incluidos el Congo e Irlanda. Dudo que le haya quedado mucho por leer de lo escrito sobre el atribulado irlandés. Pero a diferencia de una novela como La fiesta del Chivo, en que construye una ficción para que entendamos mejor la realidad histórica, en El sueño del celta, la realidad histórica, en muchos de sus aspectos, es reconocida como inverificable. Desde luego son inverificables los pensamientos secretos de Casement, a los que se libra en su celda, sus dudas de si hizo bien al ir a Alemania, su preocupación de que se puede haber vuelto loco. Cuestionables e inverificables son también sus sueños y sus aventuras sexuales. Pero Vargas Llosa, al elaborar sus hipótesis, siempre opta por lo verosímil. Es lo que hace con la de los diarios. Su hipótesis, que tiene algunas similitudes con la de W. J. McCormack ${ }^{16}$, uno de los biógrafos de Casement, de que muchas de las anotaciones son fantasías, parece razonable. Después de todo, piensa uno, ¿cómo pudo Casement haber estado con tantos hombres jóvenes día tras día, y a la vez investigar tan acuciosamente las atrocidades, y al final del día escribir 5.000 palabras sobre ellas? ¿En qué momento? ¿Y cómo lo pudo haber hecho sin ser detectado? Era altísimo, y en una ciudad de gente de estatura baja como Iquitos, tiene que haber sido tremendamente conspicuo, sobre todo que la Peruvian Amazon Company, que tenía todas las de perder con el informe que iba a preparar, lo habría seguido por todos lados. Casement, según el narrador de Vargas Llosa, era generalmente muy cuidadoso. "Tenía fama, como diplomático, de no tomar una iniciativa ni dar el menor paso sin prever todas las consecuencias posibles. Y ahora, helo aquí, atrapado en una estúpida trampa construida a lo largo de toda su vida por él mismo, para dar a sus enemi-

${ }^{16}$ W. J. McCormack, Roger Casement in Death, or Haunting the Free State, 2002. 
gos un arma que lo hundiera en la ignominia"17. ¿Será que Casement se tendió una trampa a sí mismo justamente para que tarde o temprano lo detectaran? Vargas Llosa nos deja haciéndonos preguntas como ésta para que como lectores vayamos armando nuestras propias hipótesis.

\section{La progresión ideológica de Casement}

Difícil no acordarse de la transformación ideológica del mismo Vargas Llosa al leer las descripciones de cómo va cambiando Casement. Parte al África en 1884 lleno de entusiasmo con el imperialismo británico. Quiere "salvar" a los caníbales africanos, trayéndoles comercio, cristianismo y civilización. Esa etapa de su vida corresponde de alguna manera a aquella en que Vargas Llosa se entusiasmaba con ideales colectivistas. Casement, con una sed innata de verdad y justicia como la de Vargas Llosa, va cambiando ante la evidencia empírica. Como Vargas Llosa, desilusionado cuando descubre los verdaderos motores del socialismo real impuesto por Velasco Alvarado en el Perú o por Fidel Castro en Cuba, Casement empieza a dudar cuando ve que el motor real del colonialismo es la codicia, y que para alimentarla los europeos recurren a las atrocidades más viles. Y es siempre la evidencia empírica la que manda. Para que no tengamos duda, en la novela hay incontables descripciones de las atrocidades. Sea en el Congo o el Putumayo, a los nativos que no cumplen con la cuota de caucho que se les requiere, se les corta una mano, una oreja, un falo, o los queman vivos, según la gravedad de la falta. Tanta es la degeneración a la que llegan los mandamases de Leopoldo II o de Arana, que hay casos en que mutilan a los nativos sólo para divertirse, por sadismo. En la estación Último Retiro apuestan a "quién cortaba más rápido y limpiamente la oreja de un huitoto castigado en el cepo", por ejemplo. "Velarde consiguió desorejar al indígena de un solo tajo de su machete, pero Montt, que estaba ebrio perdido y le temblaban las manos, en vez de sacarle la otra oreja le descerrajó el machetazo en pleno cráneo"18.

Casement, al ver que los europeos despojan a los africanos de su hábitat, su cultura, sus costumbres, para obligarlos a trabajar y a satisfacer su codicia por el caucho, piensa en Irlanda. Tal vez la coloni-

\footnotetext{
${ }^{17}$ Mario Vargas Llosa, El sueño del celta, p. 137.

${ }^{18}$ Ibídem, p. 229.
} 
zación de Irlanda fue menos brutal. Pero "¿no era Irlanda también una colonia, como el Congo? Aunque él se hubiera empeñado tantos años en no aceptar esa verdad que su padre y tantos irlandeses del Ulster, como él, rechazaban con tanta indignación. ¿Por qué lo que estaba mal para el Congo estaría bien para Irlanda? ¿No habían invadido los ingleses a Eire? ¿No la habían incorporado al Imperio mediante la fuerza, sin consultar a los invadidos y ocupados, tal como los belgas a los congoleses?" 19 . Es en el Congo donde empieza a interesarse por el pasado de Irlanda y a querer inmiscuirse en sus historias y leyendas. Más tarde, en el Putumayo, llegará a la conclusión de que la única forma en que los indígenas podrán salvarse de sus explotadores es a través de la lucha armada. Y esa conclusión la extenderá a Irlanda ${ }^{20}$. En todo esto hay, claro, una gran diferencia con la progresión ideológica de Vargas Llosa. Mientras que la mente de Vargas Llosa se va abriendo hasta abrazar enteramente la libertad individual, Casement cambia una ideología cerrada por otra: cambia el imperialismo británico por el nacionalismo irlandés.

\section{La exploración del mal: Casement y Conrad}

El descubrimiento de las atrocidades cometidas en el Congo y el Putumayo le hacen a Casement reflexionar sobre la naturaleza del mal. ¿Cuáles son sus causas? Tiene sobre el tema numerosas conversaciones con Edmund D. Morel. Son íntimos amigos y se dicen entre ellos Tiger (Casement) y Bulldog (Morel). ¿Hay explicaciones psicológicas, históricas, sociológicas, o proviene el mal de un pecado original inexplicable e incurable? ${ }^{21}$ Tiger es el más propenso a creer que el mal no tiene límites o remedio. Bulldog no quiere aceptar tanto pesimismo, ya que en ese caso no habría nada que hacer, lo que para él, durante años un asiduo activista que ha denunciado la crueldad de los europeos en el Congo, sería terrible. Tiger, en cambio, asume su pesimismo. Tras el conmovedor testimonio de Eponim, Thomas Campbell en Iquitos se da cuenta que aun si lograra reducir las atrocidades cometidas en el Putumayo, el mundo seguiría lleno de enclaves de salvajismo similares. "¿Se podía

\footnotetext{
${ }^{19}$ Ibídem, p. 110.

${ }^{20}$ Ibídem, p. 239.

${ }^{21}$ Ibídem, p. 196.
} 
derrotar a esa hidra? Se le cortaba la cabeza en un lugar, y reaparecía en otro, más sanguinaria y horripilante" 22 .

Es interesante comparar la exploración del mal que hace Casement con la de Joseph Conrad en su novela africana El corazón de las tinieblas (1899). Casement conoció al novelista polaco-inglés en Matadi, en 1890. Por dos semanas compartieron un cuarto. Conrad lo describe en una carta, de 1903, a su amigo antiimperialista R. B. Cunningame Graham. Se queda asombrado con la frialdad y la audacia de Casement y su visión despiadada y escéptica del mundo. "Es un irlandés protestante", escribe Conrad. "Piadoso también. Pero también lo era Pizarro." Conrad le cuenta a su amigo que le ha visto a Casement partir a la selva con dos bulldogs, y un joven cargador, sin otra arma que un bastón, para salir, meses después, sólo un poco más flaco y tostado, con los mismos perros y el mismo cargador, "tan sereno que parece que se hubiera ido a pasear en el parque". Después comenta lo mucho que tiene Casement que contar. "Cosas que he tratado de olvidar; cosas que nunca supe"23. Al Casement de Vargas Llosa, Conrad le dice "Usted me ha desvirgado, Casement. Sobre Leopoldo II, sobre el Estado Independiente del Congo. Acaso sobre la vida"24. Es que con Casement Conrad ha hablado largo sobre la explotación colonialista, y sobre los abismos de maldad a que puede llegar el ser humano. Claramente Casement le ha abierto los ojos a un Conrad todavía inocente.

Cuando en la novela Alice Stopford Green visita a Casement en Pentonville, se ponen a conversar sobre Conrad. Casement está ofendido porque Conrad no ha querido firmar la petición para conmutar su sentencia. Según Alice, Casement y Conrad tienen visiones discrepantes del mal. Conrad, en El corazón de las tinieblas, escribe "una parábola en que África vuelve bárbaros a los civilizados europeos que van allá. Tu 'Informe sobre el Congo' mostró lo contrario, más bien. Que fuimos los europeos los que llevamos allá las peores barbaries. Además tú estuviste 20 años en África sin volverte un salvaje. Incluso, volviste más civilizado de lo que eras cuando saliste de aquí creyendo en las virtudes del colonialismo y del Imperio" ${ }^{25}$. Casement la rebate con un matiz importante: "Conrad decía que, en el Congo, la corrupción moral del ser

\footnotetext{
${ }^{22}$ Ibídem, p. 163.

23 Jeffrey Meyers, Joseph Conrad: A Biography, 2001.

${ }^{24}$ Mario Vargas Llosa, El sueño del celta, p. 73.

${ }^{25}$ Ibídem, pp. 76-77.
} 
humano salía a la superficie" ${ }^{26}$. O sea la maldad es innata y el europeo llega con ella: África sólo ayuda a que florezca.

En realidad la visión que tiene Marlow, el protagonista de Conrad en El corazón de las tinieblas, es similar a la de Casement. Al llegar al Congo, Marlow describe con brutal ironía la crueldad con que los europeos tratan a los nativos. Y lo hacen, según él, por la misma razón que denuncia Casement: porque son irrefrenablemente codiciosos. En ningún caso pretende Conrad que los europeos hayan llegado buenos para entonces malearse en África. Lo que descubre es el efecto que tiene en ellos estar lejos de sus pares, y no verse sujetos a los límites que impone un vecino, una comunidad, un policía, un Estado de derecho ${ }^{27}$. Marlow parte río arriba en busca de Kurtz, un aventurero convertido en leyenda por lo salvaje que dicen que se ha vuelto. Stopford Green está implícitamente comparando a Casement con Marlow cuando afirma que este último no se volvió salvaje en África. Marlow también se compara con Kurtz. Explica que la distancia de la civilización, de la censura, de la ley, hace que Kurtz cruce un umbral, dé un salto fatal a un vacío moral y espiritual, del cual no hay retorno, mientras que él - Marlow- de alguna manera logra contenerse, logra mantenerse a este lado del abis$\mathrm{mo}^{28}$. Sin embargo ambos están en el mismo corazón de África, por lo que no es África, sino algún insondable impulso metafísico, lo que hace la diferencia. El Casement de Vargas Llosa le hace una última acotación a Stopford Green, que me parece acertada. "Yo creo que no describe el Congo, ni la realidad, ni la historia, sino el infierno" dice del Conrad de El corazón de las tinieblas. "El Congo es un pretexto para expresar esa visión atroz que tienen ciertos católicos del mal absoluto" ${ }^{29}$. En el fondo este Casement, que se va poniendo cada vez más católico, y Conrad exploran un mismo mal, el que aflora cuando no hay convenciones o fuerza que pongan límites, cuando hay impunidad, sobre todo aquella impunidad que da el poder absoluto ${ }^{30}$. Es la maldad, "la que llevamos en el alma", que describe el Dr. Dickey, un médico norteamericano que había trabajado para Arana, que Casement conoce en un barco que los lleva de Barbados a Pará: "En los países europeos y en el mío está más

\footnotetext{
${ }^{26}$ Ibídem, p. 77.

27 Joseph Conrad, Heart of Darkness, 2007, p. 60.

${ }^{28}$ Ibídem, p. 88.

${ }^{29}$ Mario Vargas Llosa, El sueño del celta, 77.

${ }^{30}$ Ibídem, p. 236.
} 
disimulada, sólo se manifiesta a plena luz cuando hay una guerra, una revolución, un motín. Necesita pretextos para hacerse pública y colectiva. En la Amazonía, en cambio, puede mostrarse a cara descubierta y perpetrar las peores monstruosidades sin las justificaciones del patriotismo y la religión. Sólo la codicia pura y dura. La maldad que nos emponzoña está en todas partes donde hay seres humanos, con las raíces bien hundidas en nuestros corazones" ${ }^{31}$. Es la maldad, claro, que Vargas Llosa ha desenmascarado en toda su obra, tal como Conrad lo hizo en la suya.

\section{El idealista quijotesco}

Uno piensa mucho en el Quijote leyendo esta novela. Por la forma en que, a pesar de su pesimismo, el Casement de Vargas Llosa quiere siempre remediar el mal. Quiere que el mundo sea mejor. Pero sobre todo por lo llevado de sus ideas que es. Quiere que el mundo sea mejor pero a su pinta. No sólo quiere, inobjetablemente, que se respeten los derechos humanos de los indígenas del Congo y del Putumayo. Como Don Quijote en su nostalgia por una supuesta Edad de Oro, quiere que Irlanda vuelva a un pasado idílico, el de sus mitos y leyendas, un pasado en que los irlandeses hablaban todos el gaélico, y en que no estaban contaminados por los ingleses. Como Don Quijote, Casement lee y lee; si bien no novelas de caballería, libros sobre la Irlanda bucólica de antaño, y trata desesperadamente, con poco éxito, de aprender él mismo el gaélico. En un barco que lo lleva a África en 1898, compone "El sueño del celta", un poema épico que denuncia el mal gobierno de los ingleses en Irlanda bajo los tudores y los estuardos ${ }^{32}$. Para acercarse más a Irlanda se va volviendo católico.

Imposible no pensar en Don Quijote al leer de este hombre "muy alto, de profundos ojos grises, delgado" 33 , que cuando finalmente decide irse a África a vivir, lo hace "de una manera exaltada", y, según le dijo su tío Edward, "como esos cruzados que en la Edad Media partían al Oriente a liberar Jerusalén" 34 . Uno se da cuenta que Casement no podría haberse quedado tranquilo trabajando detrás de un escritorio en

\footnotetext{
${ }^{31}$ Ibídem, p. 298.

32 Angus Mitchell, Casement, 2003, p. 39.

${ }_{33}$ Mario Vargas Llosa, El sueño del celta, p. 25.

34 Ibídem, p. 27.
} 
Irlanda o Inglaterra. Necesita la aventura que le da África. Después, munido de todo lo que ha aprendido en los libros sobre Irlanda en que se ha sumergido, emprenderá su viaje temerario a Alemania, a las fauces del enemigo de la Gran Bretaña que ha servido tantos años, para levantar entre los harapientos prisioneros irlandeses una brigada que ha de liberar a su país. Imposible no pensar en Don Quijote cuando, en una escena que bordea el surrealismo, el Casement de Vargas Llosa se dirige a los prisioneros irlandeses, y se sorprende cuando ellos lo pifian y hasta le escupen con indignación. En su fanático ensimismamiento, a Casement no se le ha ocurrido que es por algo que son prisioneros de los alemanes: lo son porque habían optado por pelear por los ingleses ${ }^{35}$. Más aun uno piensa en Don Quijote cuando Casement desembarca en Irlanda con su fiel escudero, el "valeroso" capitán Robert Monteith. Apenas saben remar y, en la espesa neblina de ese Viernes Santo, no avanzan en el bote en que los deja el submarino alemán ${ }^{36}$. Muy poco después de llegar a tierra, casi ahogado, Casement es descubierto por los ingleses. En su celda se quedará pensando en estas aventuras, como Don Quijote en esos ocasionales momentos en que lo vemos solo y abandonado, en toda su vulnerabilidad. Allí en su celda Casement, humillado, derrotado y frágil, se dice la verdad. "Su vida", se dice, "había sido una contradicción permanente, una sucesión de confusiones y enredos truculentos, donde la verdad de sus intenciones y comportamientos quedaba siempre, por obra del azar o de su propia torpeza, oscurecida, distorsionada, trastrocada en mentira" ${ }^{\prime 37}$.

\section{La novela del hombre completo}

Vargas Llosa cita los Motivos de Proteo de Rodó en su epígrafe al libro, para recordarnos que "cada uno de nosotros es sucesivamente, no uno, sino muchos. $\mathrm{Y}$ estas personalidades sucesivas, que emergen las unas de las otras, suelen ofrecer entre sí los más raros y asombrosos

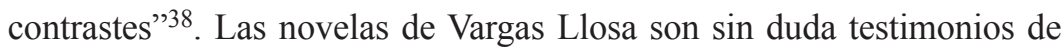
la complejidad humana, pero nunca antes había diseñado él un personaje tan complejo, tan proteico como lo es su Casement. Además, si en algún

\footnotetext{
35 Ibídem, p. 185.

${ }^{36}$ Ibídem, pp. 179, 180.

${ }^{37}$ Ibídem, p. 265.

38 Ibídem, p. 9.
} 
momento Vargas Llosa podría haber criticado esa complejidad, para no decir doblez, en esta novela la complejidad es recogida con compasión, y el doblez como un arduo desafío que el sufrido y querido protagonista está obligado a vivir. La novela, al vindicar a un hombre tan noble, pero tan complejo y tan fallido, irradia compasión. Es una doble compasión. La del mismo Casement cuando descubre con nobleza las atrocidades que se cometen contra los indígenas, y la de Vargas Llosa, que defiende a Casement contra viento y marea. Lo entiende, lo justifica, y lo vindica, sin nunca ignorar sus defectos, sus debilidades, sus ocasionales bajezas, que hacen que la vindicación sea aun más generosa.

En fin de cuentas, El sueño del celta es una novela muy humana, como tal vez ninguna de Vargas Llosa. Es una novela que rescata la humanidad, lo mejor de la humanidad, tras haber penetrado en los más infernales abismos. Es una novela en que la maldad, la miseria humana, es disecada con la misma despiadada ferocidad que en Conversación en La Catedral o en La fiesta del Chivo. Pero la profunda humanidad del protagonista la redime. La de él y la de otros. En ese sentido cabe destacar la conmovedora relación que se va estableciendo entre Casement y su carcelero, el Sheriff, que al comienzo lo trata con odio, con desprecio, por ser traidor y homosexual, pero que de a poco siente la necesidad de contarle de su hijo, que murió en la guerra a pesar de haber podido eximirse por tener los pies planos. Un hito en la relación es el día del primer aniversario de la muerte del hijo, en que el Sheriff, en un arrebato de sensibilidad, le permite a Casement ducharse.

La humanidad que hay en esta novela sobrevive al ojo clínico que tiene Vargas Llosa siempre por las humillaciones que nos depara el cuerpo, cuando se rebela contra nuestra voluntad, sea en algún acto sexual, o en un achaque inesperado, y por las humillaciones que un ser humano es capaz de depararle al cuerpo de otro: en ninguna novela de Vargas Llosa he visto tantos cuerpos salvajemente mutilados. Hacia el final hay un toque que me pareció muy especialmente típico de ese ojo clínico. El médico que asiste a la ejecución de Casement, el doctor Percy Mander, antes de autorizar el entierro, se enfunda unos guantes de plástico para explorar el ano del cadáver. "Comprobó que 'a simple vista', el ano demostraba una clara dilatación”, lo que lo lleva a concluir que quedaban confirmadas "las prácticas a las que al parecer el ejecutado era afecto" 39 . Por ser tan de Vargas Llosa esta escena, pensé

${ }^{39}$ Ibídem, p. 447. 
que - legítimamente - él la había inventado. Pero en una biografía de Casement encontré que el episodio había ocurrido ${ }^{40}$.

Comenté este hecho, en que me parecía que la ficción se cruzaba en forma particularmente asombrosa con la realidad, en una reseña que hice de la novela para el $T L S^{41}$. Pronto después llegó al editor una carta de Angus Mitchell, un biógrafo de Casement, que duda de la autenticidad de los "diarios negros". La carta de Mitchell, que es una respuesta, desde su realidad, a mi reseña de la ficción de Vargas Llosa, es magnífica. Mitchell hace una breve historia del ano de Casement. Hace un recuento de las muchas veces que fue examinado u operado ese ano, debido a los hemorroides de los que sufría. Agrega que encima de todo, los anos de los recién ahorcados están siempre dilatados. Mitchell termina su carta preguntándose si éste no era un caso de venganza de las autoridades por haber Casement penetrado y explorado las extremidades del imperialismo en África y Sudamérica ${ }^{42}$.

No me cabe duda que esta ficción de Vargas Llosa, y la realidad postulada por sus biógrafos, van a seguir entrelazándose, sobre todo cuando aparezca la traducción de la novela al inglés, y la podrán leer todos los expertos en Casement, y también incontables ingleses e irlandeses, para quienes Casement encarna un momento en la historia, en que el poderoso imperialismo británico, exhausto de esa terrible guerra de trincheras que es la Primera Guerra Mundial, empieza a perder su aplomo y a cuestionarse. Cuando ya esté esa traducción, no me cabe duda que saldrán numerosos textos como esta joya de Mitchell, y que se abrirá otra vez el debate sobre un hombre que no deja indiferente a nadie que sabe de él.

\section{REFERENCIAS}

\section{Obras citadas}

Conrad, Joseph. Heart of Darkness. Penguin, 2007.

Gallagher, David. "Mario Vargas Llosa'Latest Hero: Roger Casement”. TLS, 15 de diciembre de 2010.

McCormack, W. J. Roger Casement in Death, or Haunting the Free State. Dublin: UCD Press, 2002.

40 Séamas Ó. Síocháin, Roger Casement: Imperialist, Rebel, Revolutionary, 2008, p. 493.

41 David Gallagher, "Mario Vargas Llosa's Latest Hero: Roger Casement", $T L S, 15$ diciembre 2010.

${ }^{42}$ Angus Mitchell, Letters to the Editor, TLS, 12 de enero 2011. 
Meyers, Jeffrey. Joseph Conrad. A Biography. Cooper Square Press, 2001 [1991].

Vargas Llosa, Mario. El sueño del celta. Alfaguara, 2010.

\section{Bibliografía consultada sobre Casement}

Dudgeon, Jeffrey. Roger Casement: The Black Diaries. Belfast Press: 2002.

Foster, Roy. "Roger Casement versus the British Empire". TLS, 24 septiembre 2008.

McCormack, W. J. Roger Casement in Death, or Haunting the Free State. Dublin: 2002.

Mitchell, Angus. Sir Roger Casement's Heart of Darkness: The 1911 Document. Dublin: 2003.

- Casement. London: 2003.

(editor). The Amazon Jounal of Roger Casement. London: 1997.

Síocháin, Séamas Ó. Roger Casement: Imperialist, Rebel, Revolutionary. Dublin: 2008.

Síocháin, Séamas Ó., y Michael O'Sullivan (editores). The Eyes of Another Race: Roger Casement's Congo Report and 1903 Diary. Dublin: 2003.

Tóibín, Colm. "The Tragedy of Roger Casement". New York Review of Books, 27 de mayo 2004. 